\title{
ANALISIS SPASIAL TINGKAT BAHAYA EROSI DI WILAYAH DAS CISADANE KABUPATEN BOGOR
} (Spatial Analysis of Erosion Danger Level at Cisadane Watershed Area Bogor District)*

Oleh/By:

Tuti Herawati

\author{
Pusat Litbang Hutan dan Konservasi Alam \\ Jl. Gunung Batu No. 5 Po Box 165; Telp. 0251-8633234, 7520067; Fax 0251-8638111 Bogor \\ e-mail : tuti_hera_wati@yahoo.com \\ *Diterima : 18 Agustus 2009; Disetujui : 08 Oktober 2010
}

\begin{abstract}
This research was aimed to predict the erosion danger level at Cisadane Watershed Area based on the Universal Soil Loss Equation formula, by applying a Geographical Information System analysis. Based on the formula, we used four types of maps, i.e. rainfall, soil, slope, and land cover maps. On each map, classification was done to get four to five classes based on a specific factor standard. An overlay process was done to get the final result, i.e. erosion danger level prediction. The level was classified into five categories those were very heavy, heavy, medium, light, and very light. The results showed that the erosion danger levels at Cisadane watershed area ranged from very light to very heavy, with the percentages of the affected areas are $55.84 \% ; 15.74 \% ; 6.33 \% ; 0.81 \%$, and $0.30 \%$ respectively. The very heavy and heavy danger areas covered 316 ha. and 851 ha. respectively. Tamansari was a sub-district with the most extensive area of the very heavy danger level, i.e. 87 ha. Othersub-districts with vast heavy danger areas were Tenjolaya, Caringin, Cijeruk, and Nanggung. The results can be used as a database to make a good planning watershed area management.
\end{abstract}

Keywords: Erosion, GIS, USLE, watershed management, Cisadane

\begin{abstract}
ABSTRAK
Penelitian ini bertujuan untuk menghitung tingkat bahaya erosi di DAS Cisadane berdasarkan rumus USLE menggunakan analisis GIS. Berdasarkan rumus yang digunakan, maka diperlukan empat jenis peta sebagai dasar perhitungan tingkat bahaya erosi, yaitu peta curah hujan, peta jenis tanah, kemiringan, dan peta penutupan lahan. Pada setiap peta dilakukan klasifikasi menjadi empat atau lima kelas berdasarkan standar tertentu. Proses overlay dilakukan untuk mendapatkan hasil akhir berupa tingkat bahaya erosi yang dikategorikan menjadi lima kelas yaitu sangat ringan, ringan, sedang, berat, dan sangat berat. Hasil penelitian menunjukkan bahwa tingkat bahaya erosi di DAS Cisadane meliputi sangat ringan hingga sangat berat dengan persentase luas lahan berturut-turut dari yang sangat ringan hingga sangat berat 55,85\%; 15,74\%; 6,33\%; 0,81\%; dan 0,30\%. Lahan dengan tingkat bahaya erosi sangat berat meliputi luas 316 ha dan tingkat berat meliputi 851 ha. Tamansari merupakan kecamatan yang memiliki luas wilayah dengan tingkat bahaya erosi sangat berat terluas yaitu 87 ha. Beberapa kecamatan lain yang memiliki luas lahan dengan tingkat bahaya erosi berat adalah Tenjolaya, Caringain, Cijeruk, dan Nanggung. Hasil penelitian ini dapat digunakan sebagai data dasar untuk membuat rencana pengeolaan DAS yang baik.
\end{abstract}

Kata kunci: Erosi, GIS, USLE, pengelolaan DAS, Cisadane

\section{PENDAHULUAN}

Pengelolaan Daerah Aliran Sungai (DAS) merupakan kegiatan memperbaiki, memelihara, dan melindungi keadaan DAS, agar dapat menghasilkan barang dan jasa khususnya, baik kuantitas, kualitas, maupun kontinuitas air. Keberhasilan pengelolaan DAS diindikasikan dengan fluktuasi debit, beban sedimen sungai, serta kelestarian sumber-sumber air. Indikator lain yang juga cukup penting adalah erosi tanah. Pertahanan DAS terhadap erosi berkaitan erat dengan kegiatan pengelolaan lahan di wilayah DAS.

Erosi adalah terangkatnya lapisan tanah atau sedimen karena tekanan yang ditimbulkan oleh gerakan angin atau air pada permukaan tanah atau dasar perairan (Poerbandono et al., 2006). Pada lingkungan DAS, laju erosi dikendalikan oleh kecepatan aliran air dan sifat sedimen. Faktor eksternal yang menimbulkan erosi 
adalah curah hujan dan aliran air pada lereng DAS. Curah hujan yang tinggi dan lereng DAS yang miring merupakan faktor utama yang membangkitkan erosi.

Tingkat Bahaya Erosi (TBE) adalah perkiraan jumlah tanah yang hilang maksimum yang akan terjadi pada suatu lahan, bila pengelolaan tanaman dan tindakan konservasi tanah tidak mengalami perubahan. Analisis TBE secara kuantitatif dapat menggunakan formula yang dirumuskan oleh Wischmeier dan Smith (1978) berupa rumus Universal Soil Loss Equation (USLE).

Perhitungan TBE dengan rumus USLE sebelumnya lebih banyak digunakan untuk skala plot, namun saat ini telah juga digunakan untuk luasan lahan yang lebih besar. Analisis TBE dalam hamparan lahan seluas DAS atau sub DAS akan sangat efektif jika memanfaatkan teknologi Geographical Information System (GIS). Untuk itu dalam penelitian ini dilakukan analisis TBE secara spasial. Daerah yang dianalisis adalah Kabupaten Bogor, khususnya di wilayah DAS Cisadane.

Penelitian ini secara umum bertujuan untuk memperoleh informasi besarnya tingkat bahaya erosi di DAS Cisadane dengan menggunakan teknologi GIS. Adapun secara khusus, untuk mencapai tuju- an penelitian dilakukan kegiatan-kegiatan sebagai berikut:

1. Mengidentifikasi tingkat bahaya erosi di DAS Cisadane berdasarkan rumus USLE.

2. Menghitung luas wilayah dengan tingkat bahaya erosi tinggi di DAS Cisadane.

3. Mengidentifikasi kecamatan di DAS Cisadane dengan tingkat bahaya erosi tinggi.

Hasil penelitian ini dapat digunakan sebagai data dasar untuk membuat rencana pengeolaan DAS yang baik.

\section{BAHAN DAN METODE}

\section{A. Lokasi Penelitian}

Analisis spasial TBE dilakukan di wilayah DAS Cisadane, Kabupaten Bogor. Daerah Aliran Sungai Cisadane merupakan wilayah DAS paling luas di Kabupaten Bogor, meliputi 113.511 ha atau 36,21\% dari total luas Kabupaten Bogor. Dalam analisis ini tidak termasuk wilayah DAS Cisadane yang masuk Kotamadya Bogor. Peta wilayah DAS di Kabupaten Bogor dapat dilihat pada Gambar 1, sedangkan Tabel 1 menyajikan data luas masing-masing wilayah sub DAS di Kabupaten Bogor.

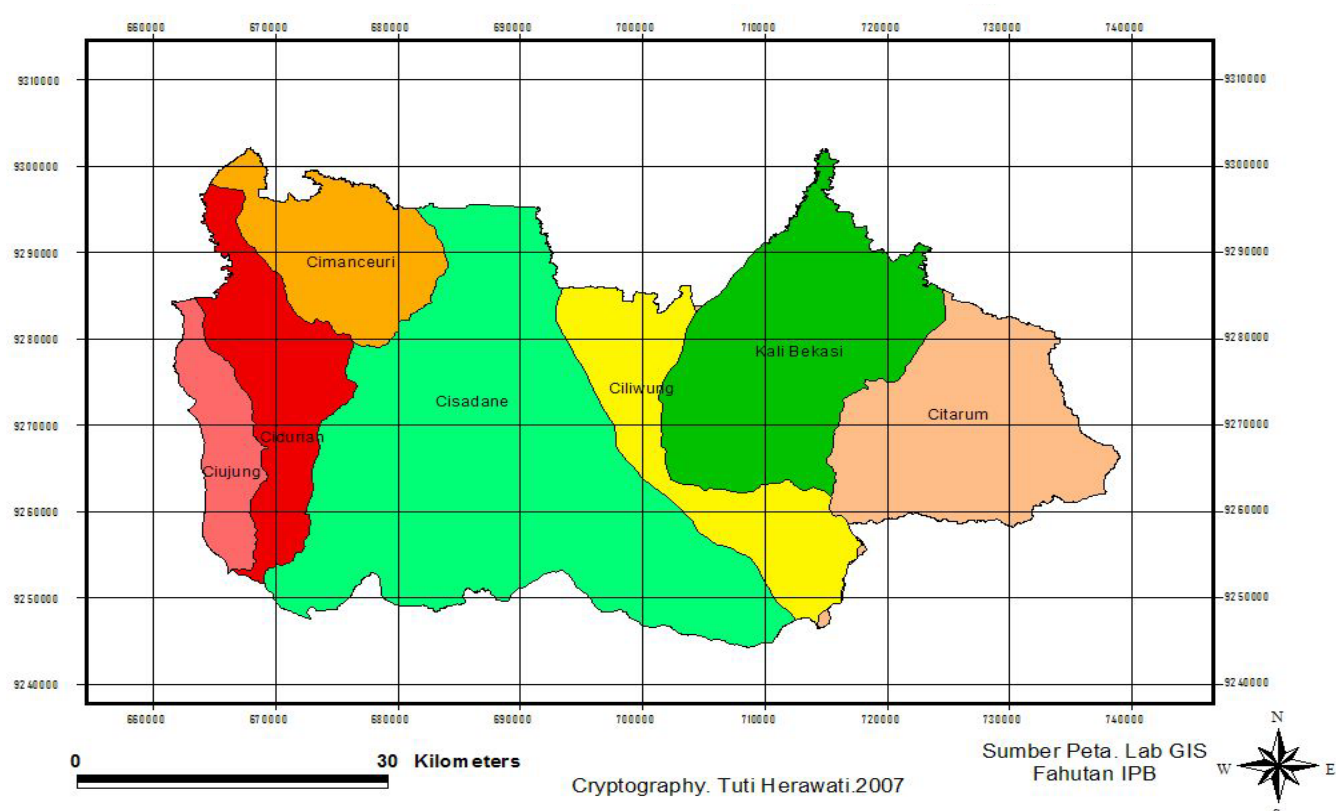

Gambar (Figure) 1. Peta DAS di Kabupaten Bogor (Map of watershed area in Bogor district) 
Tabel (Table) 1. Luas wilayah daerah aliran sungai Kabupaten Bogor (Total watershed area at Bogor district)

\begin{tabular}{lc}
\hline $\begin{array}{c}\text { Daerah aliran sungai } \\
\text { (Watershed Area) }\end{array}$ & $\begin{array}{c}\text { Luas } \\
\text { (Area) (ha) }\end{array}$ \\
\hline Cidurian & 27.336 \\
Ciliwung & 31.120 \\
Cimanceuri & 25.255 \\
Cisadane & 113.511 \\
Citarum & 44.800 \\
Ciujung & 17.291 \\
Kali Bekasi & 54.193 \\
\hline Jumlah (Total area) & 313.506 \\
\hline
\end{tabular}

\section{B. Bahan dan Alat}

Bahan yang digunakan dalam penelitian ini adalah peta Kabupaten Bogor, meliputi peta administrasi, peta wilayah DAS, peta curah hujan, peta kelas lereng, peta jenis tanah. Seluruh peta yang digunakan dalam penelitian ini merupakan hak milik laboratorium GIS Fakultas Kehutanan IPB. Proses analisis juga dilakukan di Laboratorium GIS Fakultas Kehutanan IPB. Alat analisis yang digunakan adalah perangkat lunak GIS 3.2.

\section{Metode}

Analisis TBE menggunakan rumus USLE dari Wischmeier dan Smith (1978). Formulasi USLE adalah sebagai berikut:

$\mathrm{A}=\mathrm{R} \times \mathrm{K} \times \mathrm{L} \times \mathrm{S} \times \mathrm{C} \times \mathrm{P}$

Keterangan :

$\mathrm{A}=$ Laju erosi tanah (ton/ha/tahun)

$\mathrm{R}=$ Indeks erosivitas hujan

$\mathrm{K}=$ Indeks erodibilitas tanah

$\mathrm{L}=$ Indeks panjang lereng

$\mathrm{S}=$ Indeks kemiringan lereng

$\mathrm{C}=$ Indeks penutupan vegetasi

$\mathrm{P}=$ Indeks pengolahan lahan atau tindakan konservasi tanah

Berdasarkan rumus yang digunakan, maka diperlukan empat jenis peta sebagai dasar perhitungan TBE, yaitu peta curah hujan, peta jenis tanah, kemiringan, dan peta penutupan lahan. Hubungan antara jenis peta dan faktor-faktor yang digunakan dalam perhitungan laju erosi tanah disajikan dalam Tabel 2.
Proses perhitungan nilai indeks dari setiap data peta, dilakukan dengan berbagai formulasi, yaitu:

1. Indeks erosivitas (R). Indeks erosivetas hujan dapat diperoleh dengan menghitung besarnya energi kinetik hujan (Ek) yang ditimbulkan oleh intensitas hujan maksimum selama 30 menit (EI30). Rumus yang dipergunakan adalah Metode Utomo (1989) yaitu: EI $30=-8,79+(7,01 \times$ R) dimana: EI30 = erosivitas hujan dan $\mathrm{R}=$ hujan rata-rata bulanan (cm).

2. Indeks erodibilitas (K). Indeks erodibilitas tanah menunjukkan tingkat kerentanan tanah terhadap erosi, yaitu retensi partikel terhadap pengikisan dan perpindahan tanah oleh energi kinetik air hujan. Tekstur tanah yang sangat halus akan lebih mudah hanyut dibandingkan dengan tekstur tanah yang kasar. Kandungan bahan organik yang tinggi akan menyebabkan nilai erodibilitas tinggi.

3. Indeks panjang dan kemiringan lereng (LS). Faktor kemiringan dan panjang lereng (LS) terdiri dari dua komponen, yakni faktor kemiringan dan faktor panjang lereng. Faktor panjang lereng adalah jarak horizontal dari permukaan atas yang mengalir ke bawah dimana gradien lereng menurun hingga ke titik awal atau ketika limpasan permukaan (run off) menjadi terfokus pada saluran tertentu (Renard et al., 1997).

4. Indeks penutupan vegetasi dan pengolahan lahan (CP). Faktor penutupan lahan menggambarkan dampak kegiatan pertanian dan pengelolaannya pada tingkat erosi tanah (Renard et al., 1997).

5. Kelas tingkat bahaya erosi. Hasil perhitungan nilai laju erosi dengan menggunakan rumus USLE kemudian diklasifikasi menjadi lima kelas, yaitu sangat ringan, ringan, sedang, berat, dan sangat berat. Tabel 3 menunjukkan klasifikasi TBE. 
Tabel (Table) 2. Faktor-faktor yang digunakan dalam perhitungan TBE (The variables in the erosion danger level calculation)

\begin{tabular}{lcl}
\hline \multicolumn{1}{c}{$\begin{array}{c}\text { Faktor perhitungan TBE } \\
\text { (Erosion danger level factors) }\end{array}$} & $\begin{array}{c}\text { Simbol } \\
\text { (Symbol) }\end{array}$ & \multicolumn{1}{c}{$\begin{array}{c}\text { Jenis peta } \\
\text { (Type of map) }\end{array}$} \\
\hline $\begin{array}{l}\text { Indeks erosivitas (Erosivity index) } \\
\text { Indeks erodibilitas tanah (Soil erodibility index) }\end{array}$ & $\mathrm{R}$ & $\begin{array}{l}\text { Peta curah hujan (Map of rainfall) } \\
\text { Peta tanah (Soil map) } \\
\text { Indeks nilai panjang dan kemiringan lereng (Slope- }\end{array}$ \\
$\begin{array}{l}\text { length-gradient index) } \\
\begin{array}{l}\text { Indeks penutupan vegetasi dan pengolahan lahan } \\
\text { (Crop/vegetation and management index) }\end{array}\end{array}$ & $\mathrm{LS}$ & $\begin{array}{l}\text { CP } \text { classification) } \\
\text { Peta tutupan lahan (Land cover map) }\end{array}$ \\
\hline
\end{tabular}

Tabel (Table) 3. Klasifikasi tingkat bahaya erosi (The clasification of erosion danger level)

\begin{tabular}{cccl}
\hline No. & $\begin{array}{c}\text { Kelas TBE } \\
\text { (Class of erosion danger level) }\end{array}$ & $\begin{array}{c}\text { Kehilangan tanah (Soil loss) } \\
\text { (ton/ha/th) }\end{array}$ & $\begin{array}{c}\text { Keterangan } \\
\text { (Remark) }\end{array}$ \\
\hline 1. & I & $<15$ & Sangat ringan (Very light) \\
2. & II & $16-60$ & Ringan (Light) \\
3. & III & $60-180$ & Sedang (Moderate) \\
4. & IV & $180-480$ & Berat (Heavy) \\
5. & V & $>480$ & Sangat berat (Very heavy) \\
\hline
\end{tabular}

Sumber (Source): Departemen Kehutanan (Ministry of Forestry) (1998)

\section{Pengolahan Data}

Proses pengolahan data dilakukan terhadap masing-masing jenis peta untuk memperoleh kelima jenis nilai indeks yang diperlukan dalam penghitungan tingkat bahaya erosi. Setelah keempat jenis peta selesai diolah, proses berikutnya adalah overlay seluruh peta menjadi satu peta gabungan yang menghasilkan sebaran wilayah berdasarakan nilai TBE masing-masing. Proses overlay dilakukan dengan model konvensional (Jaya, 2002; 2006).

\section{HASIL DAN PEMBAHASAN}

\section{A. Indeks Erosivitas}

Berdasarkan peta sebaran curah hujan di wilayah DAS Cisadane dapat diketahui bahwa rata-rata curah hujan bulanan berkisar antara 17-25 cm. Hampir sebagian besar wilayah memiliki rata-rata curah hujan $(\mathrm{CH})$ bulanan $25 \mathrm{~cm}$. Sebaran ratarata curah hujan bulanan disajikan pada Gambar 2.

Nilai curah hujan bulanan tersebut selanjutnya digunakan sebagai dasar untuk melakukan perhitungan indeks erosivitas dengan menggunakan rumus Utomo (1989), sehingga diperoleh nilai sebagaimana dimuat pada Tabel 4.

\section{B. Nilai Indeks Erodibilitas Tanah}

Nilai K yang digunakan mengacu pada hasil penelitian jenis-jenis tanah di Pulau Jawa yang telah dilakukan oleh Pusat Penelitian dan Pengembangan Pengairan Bandung (Lampiran 1). Berdasarkan peta sebaran jenis tanah di wilayah DAS Cisadane maka dapat dipetakan pula nilai $\mathrm{K}$ pada masing-masing satuan wilayah tersebut (Gambar 3).

\section{Indeks Panjang dan Kemiringan Lereng}

Paningbatan, Jr (2001) mencatat bahwa faktor LS dapat juga diturunkan secara bersamaan dari peta persentase kemiringan lahan (S) yang dihasilkan dengan menggunakan peta elevasi digital (Digital Elevation Map-DEM) berdasarkan persamaan: $\mathrm{LS}=0,2 \mathrm{~s}^{1,33}+0,1$, dimana $\mathrm{s}$ merupakan panjang lereng. Berdasarkan persamaan tersebut diperoleh hasil perhitungan indeks nilai LS (Tabel 5), dan pada Gambar 4 ditunjukkan peta sebaran kelas lereng lahan di wilayah DAS Cisadane. 


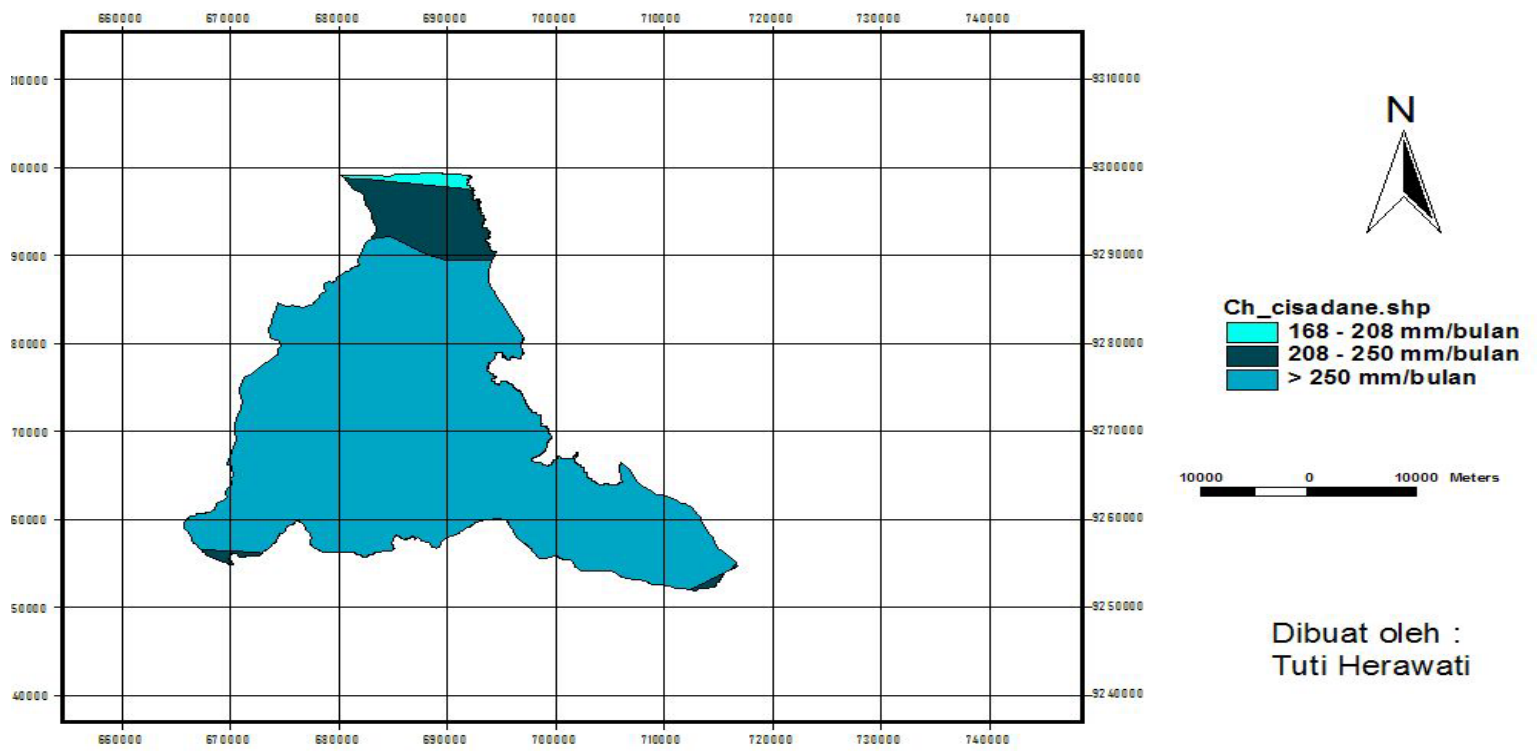

Gambar (Figure) 2. Peta curah hujan di DAS Cisadane (Rainfall map in Cisadane watershed area)

Tabel (Table) 4. Nilai erosivitas (Erosivity indeks)

\begin{tabular}{ccc}
\hline $\begin{array}{c}\text { CH tahunan (Yearly rainfall) } \\
(\mathrm{mm})\end{array}$ & $\begin{array}{c}\text { CH bulanan (Monthly rainfall) } \\
(\mathrm{cm})\end{array}$ & $\begin{array}{c}\text { Erosivitas (Erosivity) } \\
(-8,79+(7,01 \times \mathrm{R})\end{array}$ \\
\hline $1.500-2.000$ & 17 & 108 \\
$2.000-2.500$ & 21 & 137 \\
$2.500-3.000$ & 25 & 166 \\
$>3.000$ & 30 & 202 \\
\hline
\end{tabular}

Sumber (Source): Data primer diolah (Primary data)
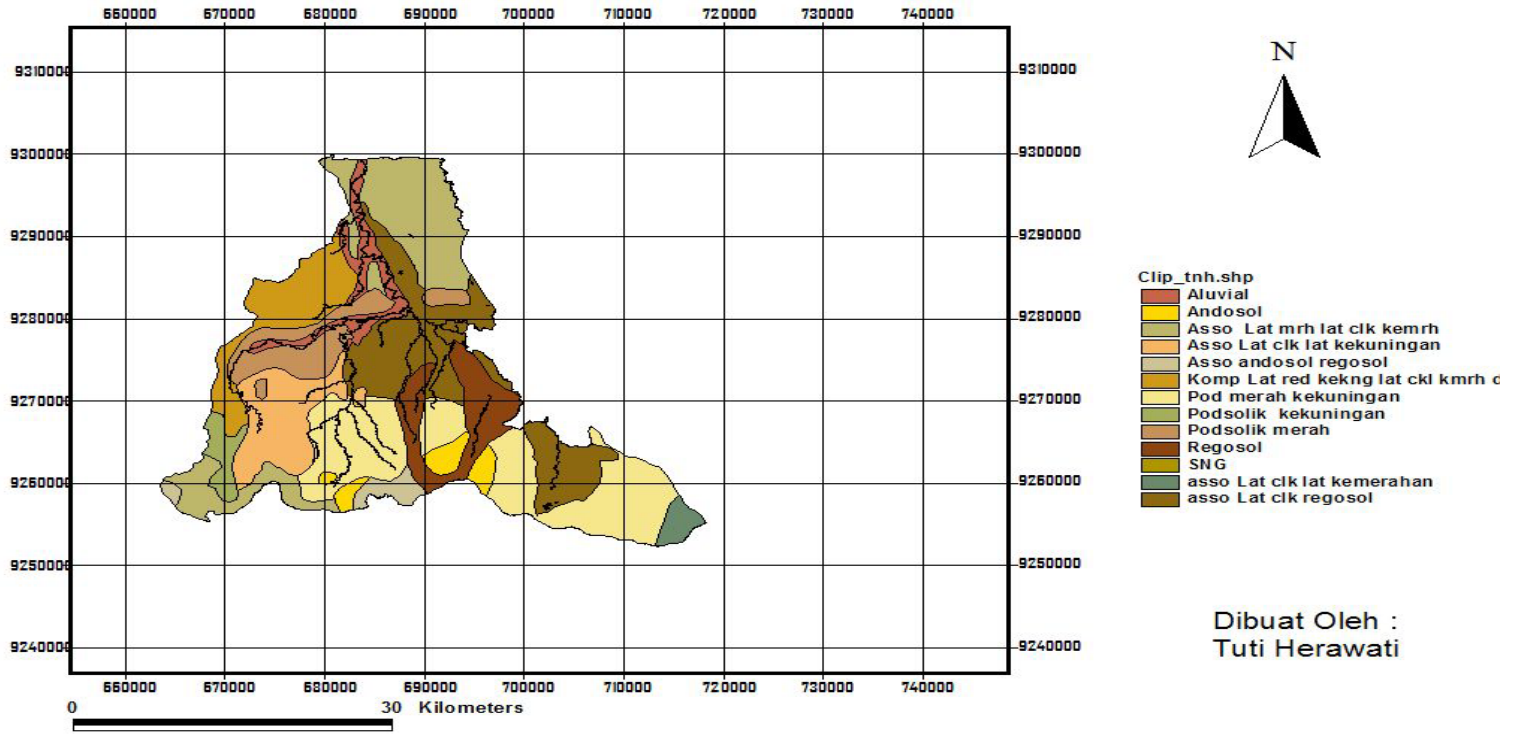

Gambar (Figure) 3. Peta jenis tanah di DAS Cisadane Kabupaten Bogor (Soil type map at Cisadane watershed area) 
Tabel (Table) 5. Indeks LS (Slope-length index)

\begin{tabular}{ccc}
\hline Kelas lereng (Class of slope) & Nilai tengah (Median) & Nilai LS (LS index) \\
\hline $0-8$ & 4,0 & 1,36 \\
$8-15$ & 11,5 & 5,25 \\
$15-25$ & 20,0 & 10,85 \\
$25-45$ & 35,0 & 22,73 \\
$45-90$ & 67,5 & 54,30 \\
\hline
\end{tabular}

Sumber (Source): Hasil olahan data primer (Primary data)

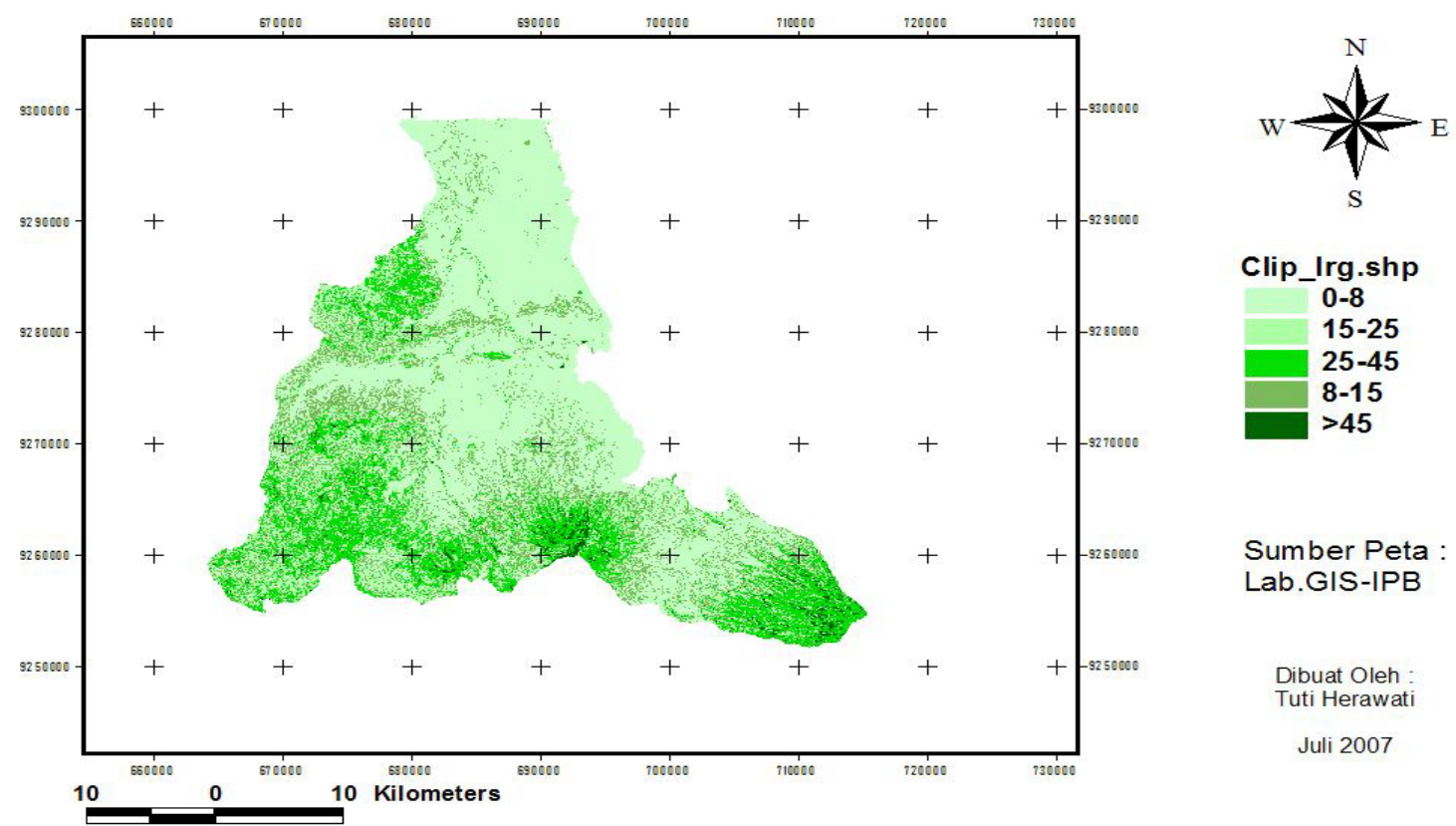

Gambar (Figure) 4. Peta kelas lereng di DAS Cisadane Kabupaten Bogor (Map of slope classification at Cisadane watershed area)

\section{Indeks Penutupan Vegetasi dan Pengolahan Lahan}

Nilai C adalah perbandingan antara rata-rata tanah tererosi dari suatu lahan yang ditanami tanaman dan teknik pengolahan tertentu terhadap rata-rata tanah tererosi dari lahan yang tanpa tanaman pada tanah, lereng, serta curah hujan yang sama. Semakin luas penutupan lahan akibat aktivitas pertanian maka semakin kecil nilai $\mathrm{C}$, demikian juga sebaliknya. Nilai $C$ diperoleh dengan membandingkan pola penutupan secara umum pada lokasi penelitian. Nilai ini merujuk pada hasil penelitian Asdak (1995) seperti disajikan dalam Lampiran 2. Faktor P atau tindakan konservasi hampir sama dengan faktor C. Saat ini dapat dikatakan bahwa tindakan konservasi pada aspek pertanian kurang dilakukan, di samping itu tindakan pengolahan tanah yang berle- bihan di DAS hulu serta meningkatkan pemukiman, merupakan faktor penyebab berkurangnya tindakan konservasi. Untuk itu dalam analisis ini akan digunakan nilai $\mathrm{P}=1$ untuk seluruh lokasi penelitian, sehingga kedua faktor ini disatukan menjadi indeks CP. Peta penutupan lahan disajikan pada Gambar 5.

\section{E. Tingkat Bahaya Erosi}

Hasil overlay peta curah hujan, jenis tanah, kelas lereng, dan tutupan lahan, diperoleh hasil peta sebaran TBE di DAS Cisadane seperti pada Gambar 6.

Dari Gambar 6 dapat dilihat bahwa wilayah DAS Cisadane sebagian besar masih termasuk dalam kelas TBE 1 atau tingkat bahaya erosi sangat ringan. Data luas lahan pada setiap kelas tingkat bahaya erosi disajikan dalam diagram pada Gambar 7 dan Tabel 6. 


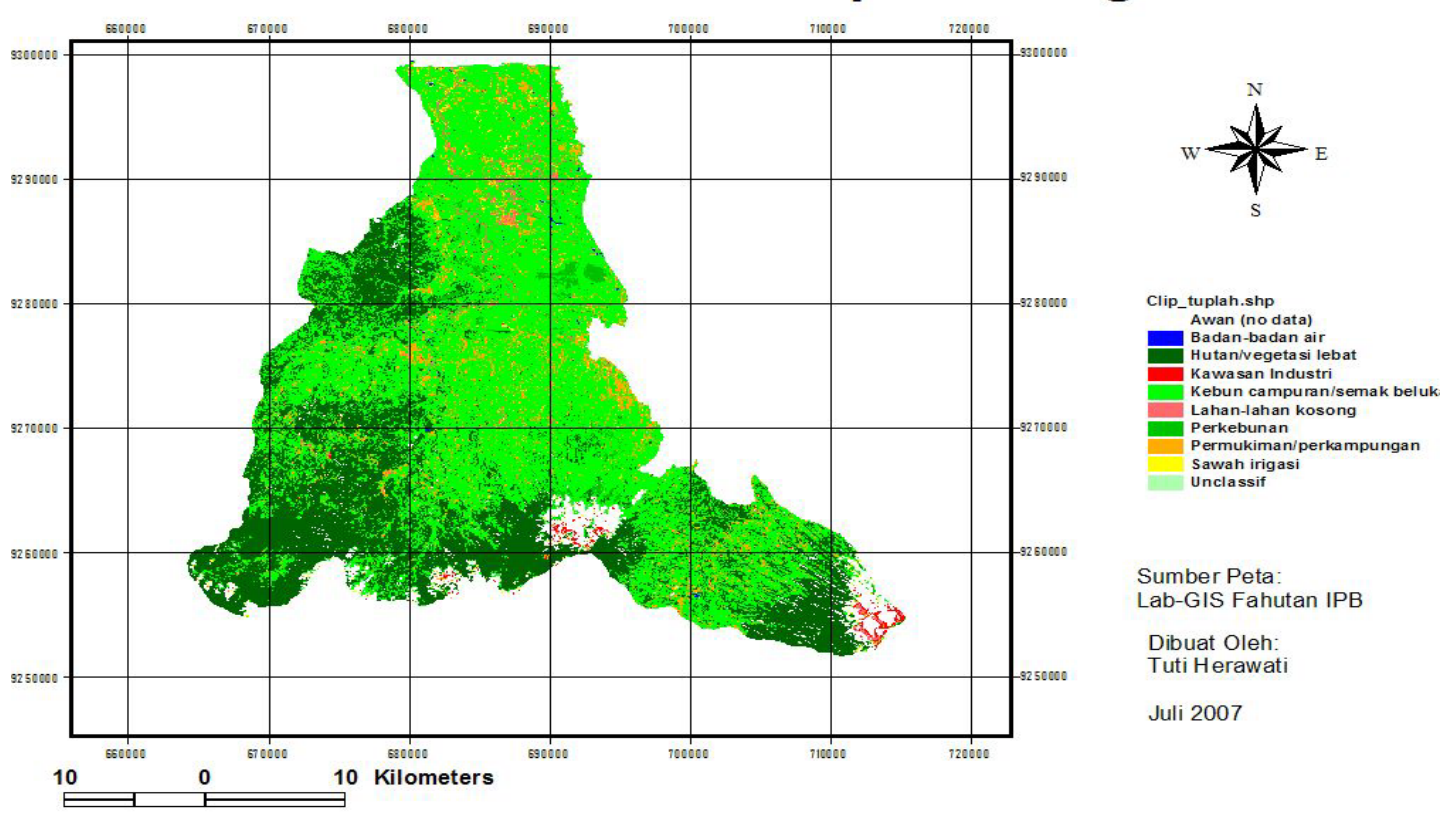

Gambar (Figure) 5. Peta penutupan lahan di DAS Cisadane Kabupaten Bogor (Land cover map at Cisadane watershed area)

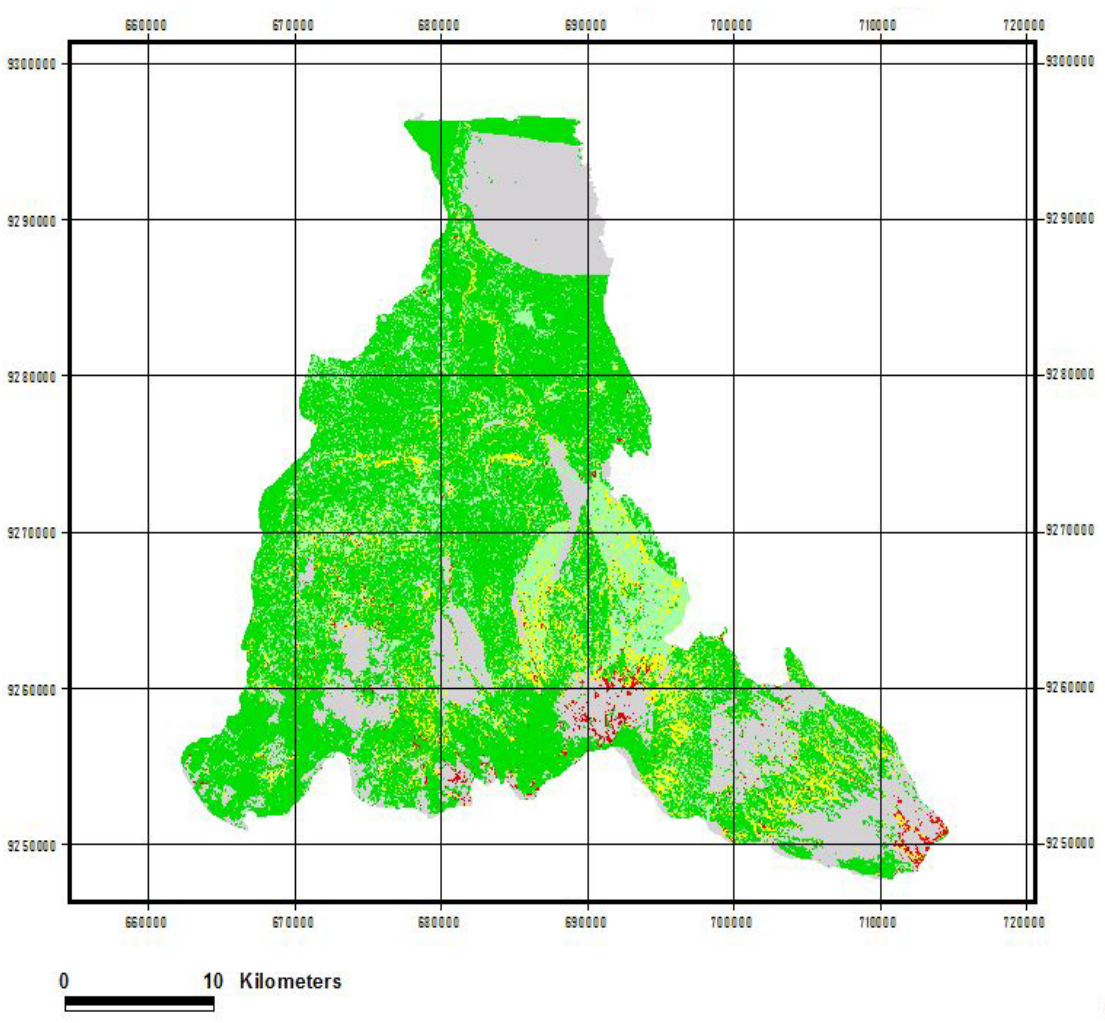

Legenda :

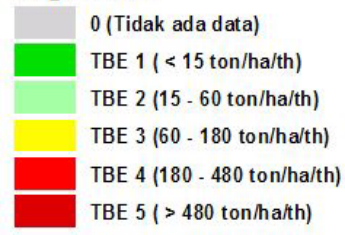

Sumber Peta

Lab GIS-Fahutan IPB

Cartography. Tuti Herawati. 200-

Gambar (Figure) 6. Peta tingkat bahaya erosi di DAS Cisadane (Map of erosion danger level at Cisadane watershed area) 


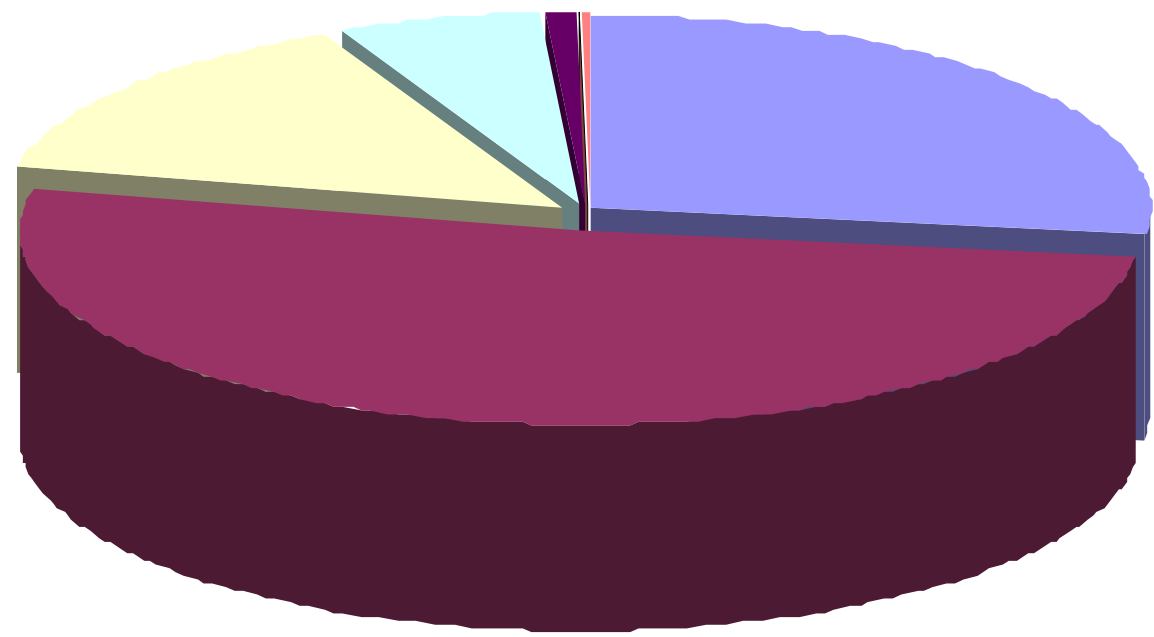

Tidak ada data

( $<15$ t/ha/th) $\square$ (15-60 t/ha/th) $\square$ (60-180 t/ha/th)

(180-480 t/ha/th)

$(>480$ t/ha/th)

Gambar (Figure) 7. Luas wilayah DAS per kelas TBE (Area of watershed for each erosion danger level)

Tabel (Table) 6. Luas lahan pada setiap kelas tingkat bahaya erosi (Area of each erosion danger level)

\begin{tabular}{lcc}
\hline Kelas TBE (Erosion danger level class) & Luas (Area) (ha) & Persentase (Percentage) (\%) \\
\hline tidak ada data (no data) & $30.820,00$ & 27,15 \\
I $:<15$ t/ha/th & $58.434,00$ & 55,84 \\
II $: 15-60$ t/ha/th & $16.467,00$ & 15,74 \\
III $: 60-180$ t/ha/th & $6.623,00$ & 6,33 \\
IV $: 180-480$ t/ha/th & 851,00 & 0,81 \\
V: $>480$ t/ha/th & 316,00 & 0,30 \\
\hline Jumlah $($ Total) & $113.511,00$ & 100,00 \\
\hline
\end{tabular}

Sumber (Source): Hasil olahan data primer (Primary data)

Berdasarkan hasil analisis TBE ini dapat dilihat juga adanya daerah seluas 27,15\% dari wilayah DAS Cisadane yang tidak dapat diketahui besaran nilai erosinya. Hal tersebut disebabkan karena adanya data kosong (no data) pada peta penutupan lahan. Sumber data untuk peta penutupan lahan berasal dari data citra, sehingga kawasan yang tidak dapat teridentifikasi tutupan lahannya adalah daerah yang tertutup awan. Wilayah dengan TBE berat (180-480 ton/ha/tahun) seluas 851 ha dan TBE sangat berat ( > 480 ton/ ha/th) seluas 316 ha.

Untuk mengetahui sebaran wilayah dengan TBE berat dan sangat berat, maka dilakukan overlay peta hasil analisis TBE dengan peta batas kecamatan. Wilayah DAS Cisadane meliputi 23 kecamatan seperti terlihat pada Gambar 8.
Berdasarkan persentase wilayah kecamatan yang tercakup dalam wilayah DAS Cisadane, dapat dikelompokkan menjadi tiga, yaitu:

1. Seluruh wilayah ada dalam wilayah DAS Cisadane (lebih dari 99\% dari total luas), yaitu Cibungbulang, Cijeruk, Dramaga, Rancabungur, Caringin, Parung, Tamansari, Leuwisadeng, dan Tenjolaya.

2. Hanya sebagian masuk di dalam wilayah DAS Cisadane, yaitu Ciawi, Cigombong, Gunungsindur, Kemang, Leuwiliang, Leuwisadeng, Nanggung, Pamijahan, dan Rumpin.

3. Sebagian kecil saja masuk di dalam kawasan DAS Cisadane, yaitu Sukajaya, Megamendung, Cigudeg, dan Tajurhalang. 


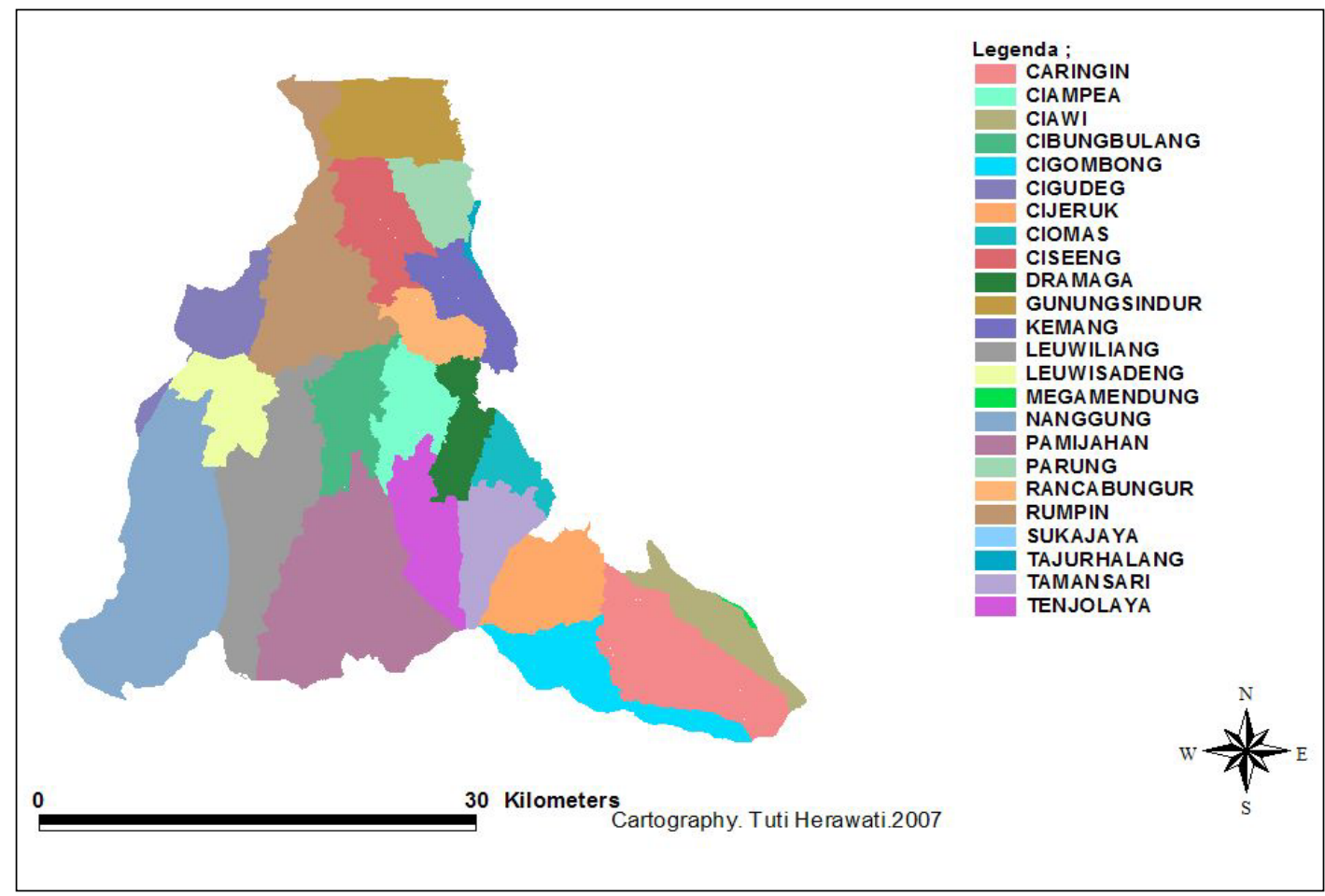

Gambar (Figure) 8. Peta kecamatan di DAS Cisadane (Map of sub distric in Cisadane watershead area)

Tabel (Table) 7. Kelas TBE di setiap kecamatan di wilayah DAS Cisadane (Erosion danger level in each sub district at Cisadane watershed area)

\begin{tabular}{|c|c|c|c|c|c|c|c|c|c|c|}
\hline \multirow{3}{*}{ No } & \multirow{3}{*}{$\begin{array}{l}\text { Kecamatan } \\
\text { (Sub district) }\end{array}$} & \multirow{3}{*}{$\begin{array}{c}\text { Luas kec. } \\
\text { (Total area } \\
\text { of sub } \\
\text { district) } \\
\text { (ha) }\end{array}$} & \multicolumn{6}{|c|}{$\begin{array}{l}\text { Luas lahan tiap kelas tingkat bahaya erosi } \\
\text { (Area of each erosion danger level) (ha) }\end{array}$} & \multirow{3}{*}{$\begin{array}{c}\text { Jumlah } \\
\text { (Total) } \\
\text { (ha) }\end{array}$} & \multirow{3}{*}{$\begin{array}{c}\text { \% Luas kec. } \\
\text { (Percentage } \\
\text { of area sub } \\
\text { district) }\end{array}$} \\
\hline & & & 0 & 1 & 2 & 3 & 4 & 5 & & \\
\hline & & & $\begin{array}{c}\text { Tdk ada } \\
\text { data } \\
\text { (No data) }\end{array}$ & $<15$ & $15-60$ & $60-180$ & $180-480$ & $>480$ & & \\
\hline 1 & Cibungbulang & 3.845 & 27 & 3.000 & 663 & 144 & 10 & 1 & 3.845 & 100 \\
\hline 2 & Cijeruk & 4.730 & 841 & 2.272 & 745 & 780 & 68 & 23 & 4.730 & 100 \\
\hline 3 & Ciomas & 1.814 & 45 & 325 & 1.162 & 278 & 5 & 0 & 1.814 & 100 \\
\hline 4 & Ciseeng & 4.130 & 987 & 2.539 & 523 & 79 & 2 & - & 4.130 & 100 \\
\hline 5 & Dramaga & 2.640 & 144 & 1.261 & 983 & 238 & 10 & 4 & 2.640 & 100 \\
\hline 6 & Rancabungur & 2.266 & 1 & 1.936 & 274 & 51 & 4 & 1 & 2.266 & 100 \\
\hline 7 & Caringin & 7.757 & 3.831 & 2.245 & 659 & 752 & 200 & 40 & 7.727 & 99,6 \\
\hline 8 & Ciawi & 4.717 & 1.134 & 1.337 & 371 & 235 & 75 & 8 & 3.160 & 70 \\
\hline 9 & Cigombong & 4.838 & 1.412 & 2.114 & 616 & 382 & 33 & 7 & 4.563 & 94,3 \\
\hline 10 & Cigudeg & 17.761 & 33 & 2.651 & 603 & 23 & 0 & - & 3.309 & 18,6 \\
\hline 11 & Gunungsindur & 4.952 & 3.721 & 1.107 & 45 & 3 & 1 & - & 4.876 & 98,5 \\
\hline 12 & Kemang & 3.367 & 8 & 2.649 & 346 & 36 & 8 & 3 & 3.049 & 90,5 \\
\hline 13 & Leuwiliang & 9.161 & 1.545 & 5.366 & 1.533 & 515 & 58 & 3 & 9.019 & 98,4 \\
\hline 14 & Leuwisadeng & 3.540 & 67 & 2.375 & 846 & 234 & 7 & - & 3.527 & 99,6 \\
\hline 15 & Megamendung & 6.243 & 16 & 37 & 13 & 11 & - & - & 78 & 1,2 \\
\hline 16 & Nanggung & 16.079 & 1.735 & 9.800 & 1.794 & 533 & 73 & 8 & 13.943 & 86,7 \\
\hline 17 & Pamijahan & 12.557 & 2.858 & 7.284 & 992 & 982 & 124 & 80 & 12.319 & 98,1 \\
\hline 18 & Parung & 2.574 & 1.915 & 618 & 39 & 2 & - & - & 2.574 & 100 \\
\hline 19 & Rumpin & 13.736 & 118 & 7.355 & 1.538 & 297 & 16 & 1 & 9.324 & 67,9 \\
\hline 20 & Sukajaya & 15.646 & - & 3 & - & - & - & - & 3 & 0,02 \\
\hline 21 & Tajurhalang & 3.095 & 41 & 139 & 4 & 0 & - & - & 184 & 5,9 \\
\hline 22 & Tamansari & 3.433 & 691 & 776 & 1.385 & 378 & 114 & 87 & 3.431 & 99,9 \\
\hline \multirow[t]{2}{*}{23} & Tenjolaya & 4.136 & 786 & 1.248 & 1.334 & 672 & 44 & 52 & 4.136 & 100 \\
\hline & Jumlah (Total) & & 21.951 & 58.433 & 16.467 & 6.623 & 851 & 316 & 104.641 & \\
\hline
\end{tabular}

Sumber (Source): Hasil olahan data primer (Primary data) 


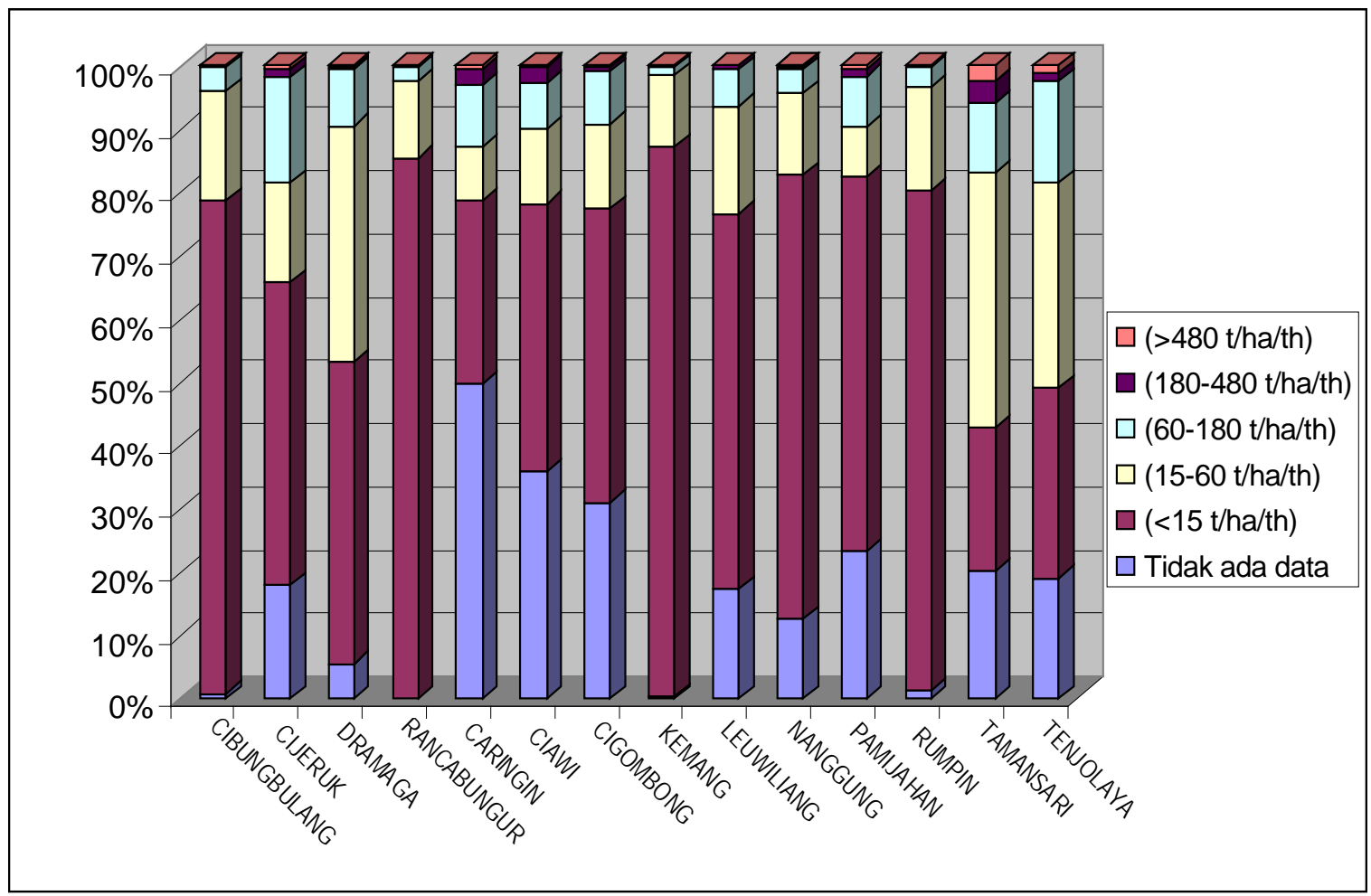

Gambar (Figure) 9. Persentase luas lahan pada tiap kelas TBE (Percentage area of eah erosion danger level)

Berdasarkan kelas TBE 5, kecamatan yang teridentifikasi memiliki luas lahan dengan tingkat bahaya erosi sangat berat berturut-turut adalah Tamansari (87 ha), Pamijahan (80 ha), Tenjolaya (57 ha), Caringin (40 ha), Cijeruk (23 ha), Nanggung dan Ciawi (masing-masing 8 ha), Cigombong (7 ha), Dramaga (4 ha), Leuwiliang dan Kemang (masing-masing 3 ha).

Kecamatan yang memiliki lahan dengan kategori TBE 4 atau berat adalah Caringin (200 ha), Tamansari (114 ha), Pamijahan (124 ha), Ciawi (75 ha), Nanggung (73 ha), Cijeruk (68 ha), Leuwiliang (58 ha), Tenjolaya (44 ha), Cigombong (33 ha), Rumpin (16 ha), Dramaga (10 ha), Kemang (8 ha), Leuwisadeng (7 ha), Ciomas (5 ha), Rancabungur (2 ha), dan Ciseeng (1 ha). Di kecamatan-kecamatan tersebut perlu segera dilakukan tindakan konservasi tanah dan perbaikan pengolahan tanah agar potensi erosi yang berat dapat ditekan.

Pada Gambar 9 ditunjukkan adanya kecamatan yang tergolong paling rawan karena memiliki lahan dengan kelas TBE sangat berat, yaitu terutama Tamansari dan Tenjolaya.

\section{KESIMPULAN DAN SARAN}

\section{A. Kesimpulan}

1. Tingkat Bahaya Erosi (TBE) di Wilayah DAS Cisadane-Kabupaten Bogor meliputi TBE 1 ( $<15$ ton/ha/tahun) sampai dengan TBE 5 (> 480 ton/ha/tahun) dengan persentase luas berturut-turut $55,84 \% ; \quad 15,74 \quad \%$; 6,33\%; 0,81\%; 0,30\%.

2. Lahan yang termasuk dalam TBE berat (erosi sebesar 180-480 ton/ha/ tahun) seluas 851 ha dan TBE sangat berat (480 ton/ha/tahun) seluas 316 ha.

3. Kecamatan yang memiliki lahan dengan TBE berat paling luas (87 ha) adalah Tamansari. Sementara itu lahan dengan TBE berat terluas terdapat di Kecamatan Caringin (200 ha). 
4. Beberapa kecamatan yang tergolong sebagai daerah rawan erosi karena memiliki kawasan dengan TBE berat dan sangat berat yang cukup luas adalah Tamansari, Tenjolaya, Caringin, Cijeruk, dan Nanggung.

\section{B. Saran}

Di kecamatan-kecamatan yang teridentifikasi sebagai wilayah yang memiliki TBE berat dan sangat berat perlu dilakukan upaya pencegahan erosi berupa tindakan konservasi tanah dan perbaikan pengolahan lahan. Di kecamatan lain yang tegolong masih relatif aman, perlu juga untuk tetap memperhatikan kegiatan pengolahan dan konservasi tanah, agar tingkat bahaya erosi tidak menjadi lebih berat.

\section{DAFTAR PUSTAKA}

Asdak. 1995. Hidrologi dan Pengelolaan Daerah Aliran Sungai jilid II. Gadjah Mada University Press. Yogyakarta.

Departemen Kehutanan. 1998. Pedoman Penyusunan Rencana Teknik Rehabilitasi Teknik Lapangan dan Konservasi Tanah Daerah Aliran Sungai. Departemen Kehutanan. Jakarta.

Jaya. 2002. Aplikasi Sistem Informasi Geografis Untuk Kehutanan. Penuntun Praktis Menggunakan
ArcInfo dan Arcview. Fakultas Kehutanan IPB. Bogor.

Jaya. 2006. Tehnik-tehnik Permodelan Spasial dalam Pengelolaan Sumberdaya Alam dan Lingkungan. Fakultas Kehutanan IPB. Bogor.

Paningbatan Jr., E.P. 2001. Hydrology and Soil Erosion Models for Catchment Research and Management. In: Maglinao, A.R., R.N. Leslie (Eds.), Soil Erosion Management Research in Asian.

Poerbandono, A. Basar, A.B. Harto, dan P. Rallyanti. 2006. Evaluasi Perubahan Perilaku Erosi Daerah Aliran Sungai Citarum Hulu dengan Pemodelan Spasial. Jurnal Infrastruktur dan Lingkungan Binaan II(2).

Renard, K.G., G.R. Foster, G.A. Weesies, D.K. McCool, and D.C. Yoder. 1997. Predicting Soil Erosion by Water: A Guide to Conservation Planning With the Revised Universal Soil Loss Equation (RUSLE). US Department of Agriculture Handbook No. 703.

Utomo. 1989. Mencegah Erosi. Penebar Swadaya. Jakarta.

Wischmeier, W.H. and D.D. Smith. 1978. Predicting Rainfal Erosion Losses A Guide to Conserrvation Planning. US Department of Agriculture. Agriculture Handbook No. 537. 
Lampiran (Appendix) 1. Nilai erodibilitas tanah (K) di wilayah Kabupaten Bogor (Erodibility index in Bogor district)

\begin{tabular}{clc}
\hline No & \multicolumn{1}{c}{ Jenis tanah (Type of soil) } & Nilai K (K index) \\
\hline 1. & Alluvial & 0,156 \\
2. & Andosol & 0,278 \\
3 & Andosol coklat kekuningan & 0,298 \\
4. & Andosol dan regosol & 0,271 \\
5 & Grunusol & 0,176 \\
6 & Latosol & 0,075 \\
7 & Latosol coklat & 0,175 \\
8 & Latosol coklat dan latosol coklat kekuningan & 0,091 \\
9 & Latosol coklat dan regosol & 0,186 \\
10 & Latosol coklat kemerahan & 0,062 \\
11 & Latosol coklat kemerahan dan latosol coklat & 0,067 \\
12 & Latosol coklat kemerahan dan latosol merah & 0,061 \\
13 & Latosol coklat kemerahan, latosol merah kekuningan dan litosol \\
14 & Podsolik kuning & 0,046 \\
15 & Podsolik kuning dan hidromorf kelabu & 0,107 \\
16 & Podsolik merah & 0,249 \\
17 & Podsolik merah kekuningan & 0,166 \\
18 & Regosol & 0,166 \\
19 & Regosol kelabu dan litosol & 0,301 \\
\hline
\end{tabular}

Sumber (Source): Puslitbang Pengairan Bandung (Centre for Irrigation Research and Development Bandung) (1985)

Lampiran (Appendix) 2. Penentuan nilai $C$ berdasarkan jenis penggunaan lahan ( $C$ index based on land use)

\begin{tabular}{clc}
\hline No. & \multicolumn{1}{c}{ Penggunaan lahan (Land use) } & Nilai C (C index) \\
\hline 1. & Hutan (Forest) & 0,001 \\
2. & Kebun campuran + talun (Taungnya system) & 0,200 \\
3. & Perkebunan teh (Tea crops) & 0,020 \\
4. & Sawah (Paddy field) & 0,010 \\
5. & Tegalan (Garden) & 0,400 \\
6. & Pemukiman (Settlement) & 1.000 \\
7. & Badan air (River, lake, etc.) & 0,010 \\
\hline
\end{tabular}

Sumber (Source): Asdak (1995) 